\title{
Synthesis and Characterization of Divalent Transition Metal Complexes Containing Thiosemicarbazone Ligands
}

\author{
PREM MOHAN MISHRA ${ }^{1}$, MANOJ KUMAR JHA ${ }^{2}$, \\ RAM SUBHAG CHAUDHARY ${ }^{3}$ and CHANDAN KUMAR ${ }^{4}$ \\ 'Department of Chemistry, (MLSM College), L. N. Mithila University, Darbhanga - 846 004, India. \\ ${ }^{2}$ At-Dighiwest, PO-lalbag, Darbhanga, Bihar, India. \\ ${ }^{3}$ Department of Chemistry, M M T M College, Darbhanga, India. \\ ${ }^{4}$ At+ PO- Kharajpur, Darbhanga, Bihar, India. \\ http://dx.doi.org/10.13005/ojc/290453
}

(Received: October 31, 2013; Accepted: December 12, 2013)

\begin{abstract}
Complexes of divalent transition metals $\mathrm{Co}(\mathrm{II}), \mathrm{Ni}$ (II) and $\mathrm{Cu}(\mathrm{II})$ with ligand 2 - hydroxy -4 - nitro acetophenone thiosemicarbazone have been synthesized. The complexes were characterized on the basis of elemental analysis, magnetic studies, electrical conductance and IR and electronic spectra. The complexes of $\mathrm{Co}(\mathrm{II})$ and $\mathrm{Ni}$ (II) were found to be octahedral where as $\mathrm{Cu}$ (II) complexes has square planer geometry.
\end{abstract}

Key words: Thiosemicarbazone, Schiff's bases, Transition metals, complex compounds.

\section{INTRODUCTION}

Thiosemicarbazones posses considerable biological properties and have medicinal applications such as anti T.B. and leprosy ${ }^{1-2}$, antiviral properties ${ }^{3}$, antitumour ${ }^{4}$, anticancer ${ }^{5,6}$. Literature survey reveals that the presence of a metal ion increases the activity of or mitigate the side effects of the parent organic compounds $^{7-10}$.

In continuation of our previous work in this communication we are going to report synthesis and characterization of complexes of $\mathrm{Co}(\mathrm{II}), \mathrm{Ni}(\mathrm{II})$ and $\mathrm{Cu}(\mathrm{II})$ with ligands containing thio semicarbozone of substituted aromatic ketones.

\section{EXPERIMENTAL}

\section{Preparation of Ligand}

4.8g of 2-hydroxy - 4 nitro - acetophenone was dissolved in methanol and treated with a solution containing $3.8 \mathrm{~g} \mathrm{BDH}$ Anal R grade thio semicarbazide hydrochloride in water.

The mixture was stirred well and refluxed for half an hour on a water bath and cooled. Pale yellow crystals was separated. The crude yellow product was recrystallised from alcohol as colourless needles. Melting point of the compound was determined by Kjeldahl's method and was found to be $491 \mathrm{~K}$. The pure and dried compound was chemically analysed. It is slightly soluble in alcohol but highly soluble in DMF but insoluble in water. 


\section{Preparation of complexes}

Calculated quantity of metal salts $(0.482$ g cobalt chloride $\mathrm{CoCl}_{2} \cdot 6 \mathrm{H}_{2} \mathrm{O}$ ) was dissolved in methanol while the ligand (HNAPTS) was dissolved in DMF. Both the solution were mixed together and $1.0 \mathrm{~g}$ sodium acetate was added to it. The solution was refluxed for about three hours and left overnight. The grey precipitate was obtained. It is filtered and washed with methanol and ice cold water. The pure complexes was dried in air.

$0.520 \mathrm{~g}$ of nickel (II) chloride was dissolved in water while $0.820 \mathrm{~g}$ ligand was dissolved in DMF. Both the solution were mixed. $1.0 \mathrm{~g}$ sodium acetate was added and refluxed for about three hours and left to stand for an hour. The red coloured precipitate was obtained. It was filtered and washed with water and ethanol and dried in air.

An ammoniacal solution of $0.256 \mathrm{~g}$ copper (II) chloride was treated with a solution of $0.348 \mathrm{~g}$ ligand (HNAPTS) dissolved in DMF. The red coloured precipitate separated was digested on the water bath for two hours and then left to stand for an hour. It was filtered washed with water and dried in air. All the three complexes were analysed chemically.

\section{RESULTS AND DISCUSSION}

Probable structure of ligand 2-hydroxy-4-nitro acetophenone thiosemicarbazone (HNAPTS)

The interpretation of I. R. spectra is quite complicated due to the presence of various similar groups and hence presence of many absorption bands. However, comparison of the spectral bands of the ligand (HNAPTS), with those of its complexes gives some important information regarding the nature of the lignad as well as the co-ordination sites through which metal ion has co-ordinated with the ligand.

The band at $3195 \mathrm{~cm}^{-1}$ in the ligand assignable to phenolic $\mathrm{O}-\mathrm{H}$ (hydrogen bonded) stretching frequency ${ }^{11}$ disappears in the $\mathrm{Ni}(\mathrm{II})$, Co (II) complexes showing deprotonation of phenolic proton. The ligand also shows strong band at $1260 \mathrm{~cm}^{-1}$ which may be attributed to the phenolic C - O vibration. A shift of this band to higher frequency $\left(\sim 1300 \mathrm{~cm}^{-1}\right)$ in the complexes indicate chelation of the ligand to metal ion through phenolic oxygen.

The sharp band at $1580 \mathrm{~cm}^{-1}$ in the free ligand due to $v_{\mathrm{C}=\mathrm{N}}$ of Schif's base residue shifts to the lower frequency at $\left(1565 \mathrm{~cm}^{-1}\right)$ in the complexes showing co-ordination through the nitrogen atom. The lowering may be very small in some cases. The ligand band at $1165 \mathrm{~cm}^{-1}$ may be assigned to $v_{\mathrm{C}=\mathrm{S}}$ group and shows downward shifting in metal complexes, indicating participation of this group in co-ordination.

The absorption band at $3380 \mathrm{~cm}^{-1}$ due to $v_{\mathrm{N}-\mathrm{H}}$ group in the free ligand remains unaltered in the complexes, indicating non-participation of this group in co-ordination.

A band present at $1385 \mathrm{~cm}^{-1}$ in the I. R. spectra of the ligand is assigned ${ }^{12}$ to $v_{C-N}$ group due to nitro group. This band remains unchanged in all the complexes, suggesting non - participation of nitro group in co-ordination.

Table 1: Elemental analysis data of ligand and complexes

\begin{tabular}{lllllll}
\hline \multirow{2}{*}{ Compound } & \multicolumn{7}{c}{ \% Observed (calculated) } \\
\cline { 2 - 5 } & $\mathbf{C}$ & $\mathbf{H}$ & $\mathbf{N}$ & $\mathbf{O}$ & $\mathbf{M}$ & \\
\hline HNAPTS & & & & & & \\
{$\left[\mathrm{Co}(\mathrm{HNAPTS})_{2}\right]$} & 37.98 & 3.76 & 20.05 & 16.73 & 11.16 & 10.32 \\
& $(38.23)$ & $(3.16)$ & $(19.83)$ & $(17.0)$ & $(11.38)$ & $(10.40)$ \\
{$\left[\mathrm{Ni}(\mathrm{HNAPTS})_{2}\right]$} & 38.43 & 3.28 & 19.47 & 17.83 & 17.83 & 10.16 \\
& $(38.25)$ & $(3.18)$ & $(19.84)$ & $(16.97)$ & $(16.97)$ & $(10.38)$ \\
{$\left[\mathrm{Cu}(\mathrm{HNAPTS}) \mathrm{NH}_{3}\right]$} & 31.80 & 3.95 & 20.18 & 15.96 & 15.96 & 18.96 \\
& $(32.36)$ & $(3.60)$ & $(20.97)$ & $(14.40)$ & $(14.40)$ & $(19.40)$ \\
\hline
\end{tabular}


Thus, we come to a conclusion that the ligand, 2 - Hydroxy - 4 - nitro acetophenone thiosemicarbazone (HNAPTS) behaves as a tridentate ligand for the metal ions, co-ordinating through (i) phenolic oxygen ( $\mathrm{C}-\mathrm{O}$ ), (ii) nitrogen atom of $(\mathrm{C}=\mathrm{N})$, of azomethine group and (iii) ketonic sulphur of $C=S$, as enolic group. Similar kind of situation has been reported by S. K. Thampy. ${ }^{13}$ This ligand is monoprotic in all the cases except $\mathrm{Ni}(\mathrm{II})$ and $\mathrm{Cu}(\mathrm{II})$ at higher $\mathrm{pH}(\mathrm{pH}=9)$. It has been observed that in these cases a band present at $1165 \mathrm{~cm}^{-1}$ in the free ligand disappears, perhaps due to deprotonation of the $\mathrm{C}=\mathrm{S}$ (enolic ) proton.

Many workers ${ }^{14-20}$ have prepared complexes with Schiff's base derived from substituted salicylaldehyde and reported non-participation of the substituents in the co-ordination. However, stability of the complex is certainly influenced by the presence of the substituents. These results are in good agreement with our previous observation ${ }^{17-24}$. The ligand may be assumed to be tautomer of the following two probable structures.

\section{Structure of complexes}

The molar conductance values of complexes 18.78 for $\mathrm{Co}(\mathrm{II}), 16.80$ for $\mathrm{Ni}(\mathrm{II})$ and 18.6 for $\mathrm{Cu}(\mathrm{II})$ suggest non-electrolytic nature of all the complexes $\left[\mathrm{Co}(\mathrm{HNAPTS})_{2}\right],\left[\mathrm{Ni}(\mathrm{HNAPTS})_{2}\right]$ and $[\mathrm{Cu}(\mathrm{HNAPTS})$ $\left.\mathrm{NH}_{3}\right]$.

\section{Electronic Spectra}

These Ni (II) complexes show four bands in their reflectance spectra favouring an octahedral stereochemistry ${ }^{25}$. Out of these four bands, three can be assigned to spin allowed $d-d$ transition, eg. ${ }^{3} A_{2 g}$ $(F) \rightarrow{ }^{3} \mathrm{~T}_{2 g}(F),{ }^{3} \mathrm{~A}_{2 g}(\mathrm{~F}) \rightarrow{ }^{3} \mathrm{~T}_{19}(\mathrm{~F})$ and ${ }^{3} \mathrm{~A}_{2 g}(\mathrm{~F}) \rightarrow{ }^{3} \mathrm{~T}_{19}$ (P). The fourth band near $10750 \mathrm{~cm}^{-1}$ is probably spin forbidden ${ }^{25}$ and may be assigned to ${ }^{2} \mathrm{~B}_{19} \rightarrow{ }^{2} \mathrm{E}_{9}$ transition.

Table 2: Melting point, Decomposition temperature, magnetic moment \& electrical conductivity data of complexes

\begin{tabular}{|c|c|c|c|c|}
\hline Compounds & M. $P(K)$ & D.T. (K) & $\mu_{\text {eff }}(B M)$ & $\wedge_{M}^{0} \mathrm{Ohm} \mathrm{cm} \mathrm{mol}^{-1}$ \\
\hline HNAPTS & 491 & - & - & - \\
\hline$\left[\mathrm{Co}(\mathrm{HNAPTS})_{2}\right]$ & - & 473 & 4.15 & 18.78 \\
\hline$\left[\mathrm{Ni}(\mathrm{HNAPTS})_{2}\right]$ & - & 533 & 3.05 & 16.80 \\
\hline$\left[\mathrm{Cu}(\mathrm{HNAPTS}) \mathrm{NH}_{3}\right]$ & 503 & 513 & 1.83 & 18.6 \\
\hline
\end{tabular}

${ }^{*}$ M.P - Melting point;D.T. - Decomposition temperature ,

$\mu_{\text {eff }}=$ Magnetic moment $\quad \wedge_{M}^{0}=$ molar conductivity

Table 3: Electronic spectral data

of complexes and their assignment

\begin{tabular}{|c|c|c|}
\hline Compound & $\overline{\mathrm{V}}\left(\right.$ in $\left.\mathrm{cm}^{-1}\right)$ & Assignment \\
\hline \multirow[t]{3}{*}[\mathrm{Co}(\mathrm{HNAPTS})_{2}]{} & 9390 & ${ }^{4} \mathrm{~T}_{1 \mathrm{~g}} \rightarrow{ }^{4} \mathrm{~T}_{2 \mathrm{~g}}(\mathrm{~F})$ \\
\hline & 19900 & ${ }^{4} \mathrm{~T}_{1 \mathrm{~g}}^{1 \mathrm{~g}} \rightarrow{ }^{4} \mathrm{~A}_{2 \mathrm{~g}}(\mathrm{~F})$ \\
\hline & 22085 & ${ }^{4} T_{1 g}^{19} \rightarrow{ }^{4} T_{1 g}^{2 g}(P)$ \\
\hline \multirow[t]{4}{*}[\mathrm{Ni}(\mathrm{HNAPTS})_{2}]{} & 11560 & ${ }^{3} A_{2 q} \rightarrow{ }^{3} T_{2 q}(F)$ \\
\hline & 17380 & ${ }^{3} \mathrm{~A}_{2 \mathrm{~g}} \mathrm{~g}(\mathrm{~F}) \rightarrow^{3} \mathrm{~T}_{1 \mathrm{~g}}(\mathrm{~F})$ \\
\hline & 26864 & ${ }^{3} \mathrm{~A}_{2 \mathrm{~g}}(\mathrm{~F}) \rightarrow{ }^{3} \mathrm{~T}_{1 \mathrm{~g}}(\mathrm{~F})$ \\
\hline & 11385 & Spin forbidden \\
\hline$\left[\mathrm{Cu}(\mathrm{HNAPTS}) \mathrm{NH}_{3}\right]$ & 20,000 & ${ }^{2} \mathrm{~B}_{1 \mathrm{~g}} \rightarrow 2 \mathrm{~A}_{1 \mathrm{~g}},{ }^{2} \mathrm{E}_{\mathrm{g}}$ \\
\hline
\end{tabular}


Table 4: IR Spectral bands $\left(\mathrm{cm}^{-1}\right)$ of ligand and complexes

\begin{tabular}{|c|c|c|c|c|}
\hline \multirow{2}{*}{$\begin{array}{l}\text { Ligand } \\
\text { HNAPTS }\end{array}$} & \multicolumn{4}{|c|}{ Complexes } \\
\hline & {$\left[\mathrm{Co}(\mathrm{HNAPTS})_{2}\right]$} & {$\left[\mathrm{Ni}(\mathrm{HNAPTS})_{2}\right]$} & {$\left[\mathrm{Cu}(\mathrm{HNAPTS}) \mathrm{NH}_{3}\right]$} & Assignment \\
\hline 3380 & 3380 & 3385 & 3380 & $\begin{array}{l}\mathrm{N}-\mathrm{H} \\
\text { stretching }\end{array}$ \\
\hline 3195 & & & & $\begin{array}{l}\mathrm{O}-\mathrm{H} \\
\text { (H- bonded) }\end{array}$ \\
\hline 3090 & 3105 & 3100 & 3105 & $\begin{array}{l}\mathrm{C}-\mathrm{H} \\
\text { stretching }\end{array}$ \\
\hline 1580 & 1575 & 1570 & 1580 & $\begin{array}{l}\mathrm{C}=\mathrm{N} \\
\text { stretching }\end{array}$ \\
\hline 1405 & 1415 & 1400 & 1410 & $\mathrm{~N}-\mathrm{H}$ bending \\
\hline 1385 & 1395 & 1390 & 1395 & $\mathrm{C}-\mathrm{N}$ stretching \\
\hline 1260 & 1305 & 1285 & 1285 & $\begin{array}{l}\mathrm{C}-\mathrm{O} \\
\text { (phenolic) }\end{array}$ \\
\hline 1195 & & & 1205 & Skeletal in \\
\hline 1175 & & & 1175 & $\begin{array}{l}\text { plane } \\
\text { vibrations }\end{array}$ \\
\hline 1155 & 1145 & 1140 & 1135 & $\mathrm{C}=\mathrm{S}$ stretching \\
\hline 11351065 & 11401070 & 11301070 & 11251075 & Characteristic vibration \\
\hline 1045 & 1050 & 1040 & 1030 & $\begin{array}{l}\text { of } 1,2,4- \\
\text { trisubstituted } \\
\text { benzene ring }\end{array}$ \\
\hline $910-920$ & $920-930$ & $915-925$ & $910-920$ & $\mathrm{C}-\mathrm{N}$ bending \\
\hline \multirow[t]{4}{*}{820} & 820 & 820 & 820 & $\begin{array}{l}\text { Skeletal } \\
\text { vibrations }\end{array}$ \\
\hline & 530 & 540 & 535 & $\mathrm{M}-\mathrm{N}$ bond \\
\hline & 505 & 480 & 495 & $\mathrm{M}-\mathrm{O}$ bond \\
\hline & 375 & 330 & 285 & $M-S$ bond \\
\hline
\end{tabular}

Copper (II) has $\mathrm{d}^{9}$ configuration which makes $\mathrm{Cu}$ (II) subject to John - Teller distortion, if placed in an environment of cubic like regular octahedral or tetrahedral symmetry and this has a profound effect on all its stereochemistry ${ }^{27}$.

The typical distortion is an elongation along one four fold axis, so that there is planar array of four short $\mathrm{CU}-\mathrm{L}$ bonds with two trans long ones. In the limit of course, the elongation leads to a situation indistinguishable from square co - ordination as found in many discrete complexes of $\mathrm{Cu}$ (II). Thus the cases of tetragonally distorted "Octahedral" co - ordination and square co - ordination cannot be sharply differentiated.
Because of the relatively low symmetry of the environments in which the $\mathrm{Cu}^{2+}$ ion is characteristically found, detailed interpretation of spectra and magnetic properties are somewhat complicated even though one is dealing with the equivalent of a one - electron case.

The molar conductance values suggest non - electrolytic nature of this complex while I.R. band near $655 \mathrm{~cm}^{-1}$ suggests $\mathrm{M}-\mathrm{NH}_{3}$ bonding.

The magnetic moment of $\mathrm{Cu}$ (II) complex correspond well with the presence of one unpaired electron and gives on specific information about their stereochemistries. The $\mu_{\text {eff }}$ value of Co(II) complex (4.15 BM) indicate the presence of three unpaired electron in the complex whereas $\mu_{\text {eff }}$ for $\mathrm{Ni}(\mathrm{II})$ complex 


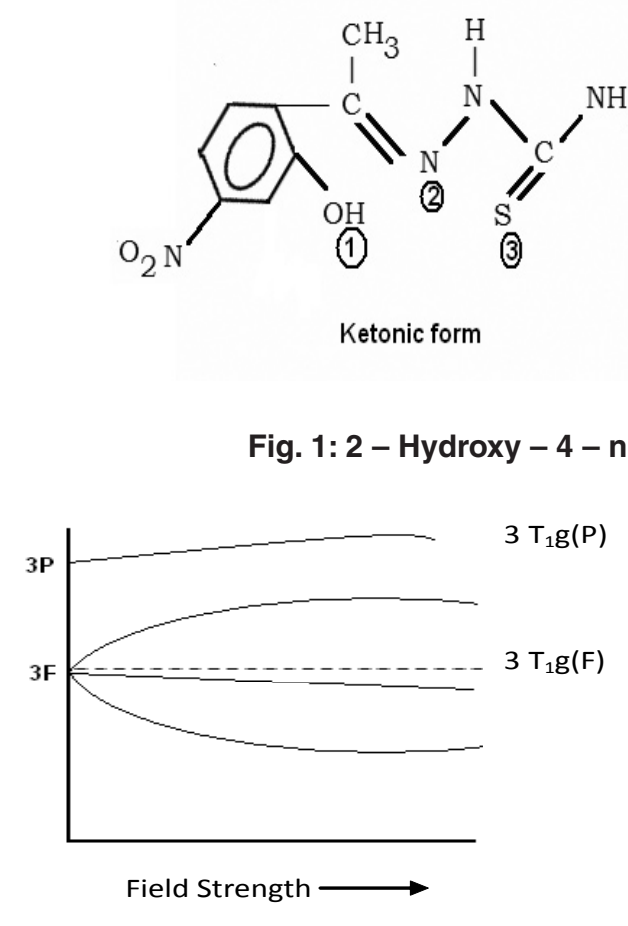

Fig. 2: Orgel diagram of $\mathrm{Ni}(\mathrm{II})$ complex

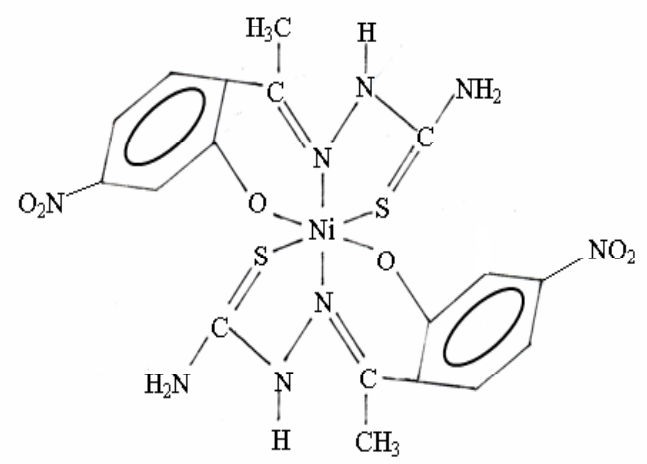

Fig. 4: Bis - (2- hydroxy - 4 - nitro acetophenone thio semicarbazone) $\mathrm{Ni}(\mathrm{II})$

(3.05 BM) suggests presence of two unpaired electron in the complex.

Taking all these facts into consideration, along with their elemental analysis data the most probable structures of these complexes are given below in figure $3,4 \& 5$.

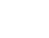<smiles>C/C(=N/NC(=N)S)c1ccc([N+](=O)[O-])cc1O</smiles>

enolic form 


\section{REFERENCES}

1. Parekh,A K. and Desai K.K.: Indian J. Chem.; 45B: 1072 (2006).

2. Chandra S. and Gupta L.K.: Spectrochimica Acta Part A.;62: 1089 (2005).

3. Demertzi D.K., Miller J.R., Kourkoumelis N., Hadzikaaou S.K. and Demertzis M.A: Polyhedron 1999; 18: 1005.

4. Ferrari B.M., Fava G.G. Leporti E., Pelosi G., Rossi R., Tarasconi P., Albertini R., Bonati A., Lunghi P. and Pinelli S.: J. Inorganic Biochem:; 70: 145 (1998).

5. Ferrari M.B., Capacchi S., Reffo G., Aelosi G., Tarasconi P., Albertini R., Pinellis S., Lunghi P.: J. of Inorg. Biochem. 81: 89 (2000).

6. Bhat A.K., Bhamaria R.F., Patel M.R. Bellare R.A. and Deliwala C.V.:Indian J. chem.10: 694 (1972).

7. Lobana T.S., Rekha, Butcher R.J., Castineiras A., Bermejo E. and Bharatam P.V.: Inorg. Chem.; 45: 1535 (2006).

8. Sharma S., Athar F., Maurya M.R., Azam A.: European J. Med. Chem. 40: 1414 (2005).

9. Klayman D.L., Bartosevich J.F., Griffine T.S., Mason C.J. and Scovill J.P: J. Med. Chem.22: 854 (1979).

10. Klayman D.L., Scovill J.P., Bruce J. and Bartosevich J: J. Med. Chem.; 27: 84 (1984).

11. Purushottam B.Chakrawarti and Pramila Khanna : J. Ind. Chem. Soc., 59: 828 (1982).

12. A. Syamal and B.K.Gupta J.Ind. Chem. Soc., 59: 697 (1982).

13. S. K. Thampy, Ph.D. Thesis, Bhavnagar University, Gujrat

14. B. K. Rai, Sapana Kumari, R. K. Singh, A. Prasad, M. P. Sinha \& P. M. Mishra : Journal of Ultra Chemistry, Bhopal, M.P. 5(1): 83-88
(2009).

15. Shiva Shakti, P.M. Mishra, S. K. Mishra, A. K. Jha: Asian Journal of Chemistry, Ghaziabad, U.P. 22(7): (2010)

16. Shiva Shakti, Md. S. Raza, D. K. Jha \& P. M. Mishra: Journal Of Ultra Chemistry, Bhopal, M.P. 7(1): 113-122 (2011).

17. Om Prakash, Bal Krishan and George Jacob, Orient J. Chem., 29(2): 823-828 (2013).

18. P. M. Mishra, Shiv Shakti, S. K. Choudhary, Gunjan Vikash, G. Singh, J. P. Mishra \& Sudha Kumari: Journal of Ultra Chemistry, Bhopal , M.P. 8(2): 195-204 (2012).

19. P. M. Mishra, D. K. Choudhary, Shiva Shakti \& J. J. Choudhary: Journal of Ultra Chemistry, Bhopal, M. P. 8(3): 415 -420 (2012).

20. P. M. Mishra : Journal of Ultra Chemistry, Bhopal (M.P), 8(3): 401-408 (2012).

21. P. M. Mishra : Oriental Journal of Chemsitry, Bhopal, M.P. 29(2): p- 677 - 683. 2013.

22. Liberta A. E. and West D.X: BioMetal 5: 121 (1992).

23. West D.X., Brain G.A., Jasinski J.P., Li Y., Pozdniakiv R.Y., Martinez J. V., Toscano R.A. and Ortega S. H.: Polyhedro; 15; 665 (1996).

24. A.B.P. Lever : "Inorganic Electronic Spectroscopy", Elsevier, London (1968)

25. J.A. Bertrand and P.G. Eller : Inorg. Chem., (13) 927 (1974).

26. S.A. Cotton : Co-ord. Chem. Rev., 8: 167 (1972).

27. F. Cotton and G. Wilkinson : "Advanced Inorganic Chemistry”, Weley Estern Ltd., London, VII Ed. (1984).

28 B.J. Hathaway and D.E. Billing: Co - ordination Chem. Rev, 5: 143 (1970). 